\title{
A qualitative and quantitative comparison of adverse drug reaction data of anti-epileptic drugs in various sources of drug information
}

\author{
Keerat Kaur Kullar ${ }^{1}$, Prabhsimran Kaur ${ }^{2 *}$, Aanandita Singh ${ }^{3}$, Gurpreet Kaur Randhawa ${ }^{2}$
}

${ }^{1}$ Department of Anesthesia, ${ }^{1,3}$ Shri Guru Ram Das Institute of Medical Sciences and Research, Amritsar, Punjab, India ${ }^{2}$ Department of Pharmacology, Govt. Medical College, Amritsar, Punjab, India

Received: 22 November 2019

Accepted: 13 January 2020

\section{*Correspondence:}

Dr. Prabhsimran Kaur,

Email: prabh93simran@gmail.com

Copyright: () the author(s), publisher and licensee Medip Academy. This is an open-access article distributed under the terms of the Creative Commons Attribution Non-Commercial License, which permits unrestricted non-commercial use, distribution, and reproduction in any medium, provided the original work is properly cited.

\begin{abstract}
Background: It is essential to spread awareness about known adverse drug reactions (ADRs) for identification, prevention and their proper management. The aim of this study is to assess disparities in documented ADRS of antiepileptic drugs in various sources of drug information.

Methods: An observational, cross sectional study was done to compare different drug information sources for ADRs. Six sources of information namely: National Formulary India (2011), Drug Today (2018), Current index of medical specialties (CIMS), and some textbooks like Lippincott's illustrated reviews: Pharmacology (2012), Brenner and Stevens' Pharmacology (2018) and George and Goodman and Gilman's (GG): The pharmacological basis of therapeutics (2018) were critically analysed for ADRs of a total of 34 drugs. Prototype drugs and most commonly prescribed antiepileptic drugs, were chosen for study. They were categorized according to therapeutic classification and guidelines by Indian Society of Epilepsy. ADRs were categorized according to various body systems, and serious and life threatening ADRs, then were tabulated and compared. Qualitative and quantitative analysis of this data was also done.

Results: None of analysed sources mentioned all antiepileptic drugs. GG contained information for maximum number of drugs studied (76.4\%) and National Formulary of India gave information for (52.9\%) drugs only. There was wide variability among various resources while listing ADRs. CIMS listed maximum number of ADRs (85.5\%) while minimum was included in Brenner and Stevens' Pharmacology (13\%) for all antiepileptic drugs. The quality of data though limited was relatively better in CIMS, but none of sources studied were found to be complete.

Conclusions: No source of information provided complete information about adverse effects of all 34 anti-epileptic drugs. Academicians and policymakers can work towards providing complete ADR information in all sources of information and updating it from time to time. Thus, making drug use safer in patients of epilepsy.
\end{abstract}

Keywords: National Formulary India, Current index of medical specialties, The pharmacological basis of therapeutics

\section{INTRODUCTION}

Epilepsy occurs in about 70 million people worldwide out of which around 12 million people are Indians, which constitutes one-sixth of the global burden. ${ }^{1}$ Since antiepileptic drugs have a narrow therapeutic index and their adverse effects can affect any organ, so proper knowledge of these adverse effects is vital for safe use of drugs. Patients on chronic treatment of antiepileptic drugs showed 10 to $40 \%$ prevalence when tolerability is evaluated by means of spontaneous reports, and 60 to 95\% when adverse effects are evaluated by using a checklist. $^{2}$ 
All pharmacologically active moieties are known to produce adverse drug reactions (ADRs), which can be mild, severe or even life threatening. ADRs are not rare; an incidence of 10 to $25 \%$ has been documented in different clinical settings. ${ }^{3}$ WHO defines an ADR as "A response to a drug which is noxious and unintended and which occurs at doses normally used in man for the prophylaxis, diagnosis or therapy of disease, or for the modification of physiological function". 4 Proper knowledge of existing ADRs is essential for the rational and safe use of medicines. Often, complete information regarding ADRs is lacking or variable in different sources of information in literature. Due to lacunae in a single credible source, it may lead to all ADRs not being identified or could be ignored, leading to unsafe use of medicines.

Antiepileptic drugs owing to their narrow therapeutic index have significant safety implications and ADRs have a negative impact on quality of life of patients. The Food and Drug Association categorizes a serious adverse event (events relating to drugs or devices) as one in which "the patient outcome is death, life-threatening (real risk of dying), hospitalization (initial or prolonged), disability (significant, persistent, or permanent), congenital anomaly, or required intervention to prevent permanent impairment or damage."5 Serious adverse events of antiepileptic drugs may include fulminant hepatitis, splenomegaly, neurological side effects, haematological disorders, pneumonitis and behavioural symptoms. A suspected adverse reaction is considered "life threatening" if the patient is at substantial risk of dying at the time of the adverse event, or use or continued use of the device or other medical product might have resulted in the death of the patient. ${ }^{6}$ Life threatening adverse events of antiepileptics include Stevens Johnson syndrome, arrhythmias, heart block, acute renal failure, hepatic failure, status epilepticus, and respiratory and cardiovascular collapse.

Pharmacovigilance, is defined as "the science and activities relating to the detection, assessment, understanding, and prevention of adverse effects or any other drug-related problem" (World Health Organization, 2018), and it depends mainly on spontaneous reporting. Earlier, reporting of ADRs was limited to healthcare professionals which has now started dedicated platforms for patients in last decade to report any adverse event with drug use. However, under-reporting and incomplete data are still major limitations for Pharmacovigilance Program of India. ${ }^{7}$

For safe use of medicines, awareness regarding the existing knowledge of ADRs is essential to identify and manage them. Sources of ADR information available for physicians are standard textbooks, National formularies, drug information compendia, drug advertisement brochures and online search engines. Textbooks usually provide information of drugs as a class. Online search is easily accessible but with questionable authenticity and advertisement brochures are often biased. The criteria for inclusion of drugs in the NFI are drugs from the National list of essential medicines 2011, India, drugs used in national health programs, drugs listed in Indian Pharmacopoeia, drugs not covered but recommended by a panel of experts, and any drug (s) considered appropriate by the International Patent Classification. Therefore, all drugs of a class may not find mention in the NFI. Prescribers usually follow commercially available drug information compendia whose completeness and quality of data should be assessed. Drug information available in various sources should be uniform, reliable, and conforming to the regulatory label of the drug.

ADR reporting leading to generation of drug alerts, which stands on the pillars of adequate knowledge of ADRs related to specific drugs in authentic sources of information, especially which are easy to refer to by the busy prescriber. Antiepileptic drugs were selected for the study as they are significantly related to toxicity. The present study is designed to assess the variation or adequacy in the documented ADRs of antiepileptic drugs in various sources of drug information including textbooks.

\section{METHODS}

An observational and cross-sectional study was carried out to compare different sources of drug information for ADRs. Six varied sources of information like National Formulary of India (NFI) 2011, Drug Today (DT) 2018, current index of medical specialties (CIMS) 2019, Lippincott's Illustrated Reviews: Pharmacology (2012), Brenner \& Stevens' Pharmacology (2018) and Goodman Gillman's Pharmacological Basis of Therapeutics (GG) (2018) were analysed for ADRs of 34 antiepileptic drugs. ${ }^{8-13}$ ADRs were categorized according to body systems, tabulated and compared. The ADRs were categorized according to various body systems such as central nervous system, cardiovascular system, and gastrointestinal system. ADRs of all the drugs were compared in different sources. Quantitative and qualitative analysis of ADRs including serious and life threatening ADRs were done. Parameters assessed were number of drugs out of 34 mentioned in the sources, total number of ADRs and percent ADRs mentioned for all individual drugs in these 6 sources of information and total number of serious and life threatening ADRs and percent serious and life threatening.

ADRs mentioned for all individual drugs in these 6 sources of information.

\section{RESULTS}

Six sources of information namely NFI, DT, CIMS, Lippincott, Brenner \& Stevens' Pharmacology and GG were analysed for the available ADR information of the 34 antiepileptic drugs mentioned therein. 


\section{Quantitative analysis}

Maximum number of anti-epileptic drugs are mentioned in GG $(76.4 \%)$ followed by CIMS $(73.5 \%)$, Lippincott (67.6\%), DT (64.7\%), Brenner \& Stevens' Pharmacology $(61.7 \%)$ and NFI (52.9\%). None of the sources of information had included all the anti-epileptic drugs. Maximum ADRs were included in CIMS (85.5\%) and least in Brenner and Stevens' Pharmacology (13.0\%) (Figure 1). NFI, though has mentioned all anti-epileptic drugs but it has been found to be deficient in providing details of ADRs.

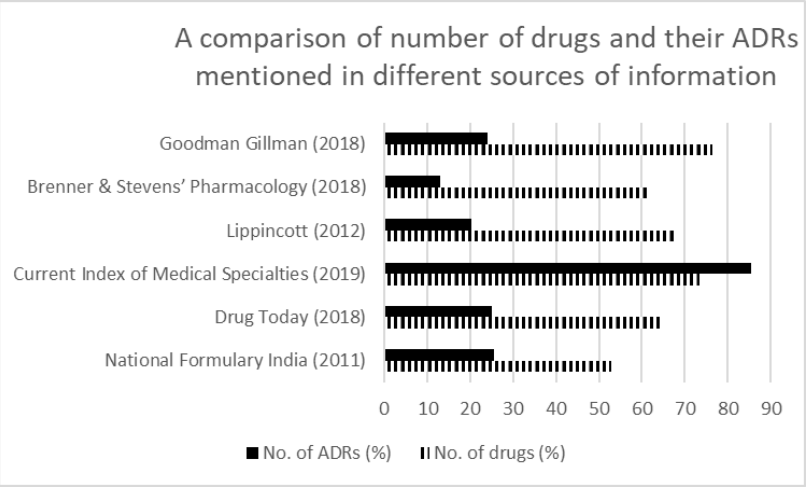

In treatment guidelines of Indian Epilepsy Society, 22 anti-epileptic drugs are mentioned. 7 other drugs are divalproex, primidone, felbamate, acetazolamide, magnesium sulfate, clorazepate and pregabalin were also evaluated. Number of other drugs mentioned in these sources of information are CIMS (5), GG (5), Brenner \& Stevens (5), DT (3), Lippincott (3) and NFI (1).

\section{Qualitative analysis}

These sources of information lack data regarding many important drugs, such as midazolam in DT, NFI and GG, eslicarbazepine in NFI, Lippincott, CIMS and GG, oxcarbazepine in DT and Brenner and Stevens' Pharmacology, lacosamide in DT, CIMS \& Brenner \& Stevens' Pharmacology, and clobazam in Lippincott and Brenner \& Stevens' Pharmacology and GG. CIMS has not mentioned a few drugs like eslicarbazepine, lacosamide, pentobarbital, perampanel and rufinamide. Lippincott has not mentioned clobazam, Eslicarbazepine and perampanel. GG had included 12 newer antiepileptics followed by DT (10) while a fewer number of newer drugs are mentioned in the other sources under study (9 by CIMS and Lippincott, and 8 by NFI and Stevens and Brenner) (Table 1).

Figure 1: Comparison of number drugs and their ADRs mentioned in different sources of information.

Table 1: Comparison of total number of adverse effects of antiepileptic drugs mentioned among different sources of information (classification of seizures and treatment is as per guidelines of Indian Epilepsy Society $(2017)^{8}$ ).

\begin{tabular}{|c|c|c|c|c|c|c|c|c|}
\hline \multirow[t]{2}{*}{ S.no } & \multirow[t]{2}{*}{ Drugs } & \multirow{2}{*}{$\begin{array}{l}\text { Total } \\
\text { ADRs }\end{array}$} & $\mathrm{NFI}^{8}$ & $\mathbf{D T}^{9}$ & CIMS $^{10}$ & Lippincott $^{11}$ & $\begin{array}{l}\text { Brenner \& } \\
\text { Stevens }^{12}\end{array}$ & $\mathbf{G G}^{13}$ \\
\hline & & & $\mathbf{N}(\%)$ & $\mathbf{N}(\%)$ & $\mathbf{N}(\%)$ & $\mathbf{N}(\%)$ & $\mathbf{N}(\%)$ & $\mathbf{N}(\%)$ \\
\hline 1 & Brivaracetam & 6 & $0(0)$ & $0(0)$ & $0(0)$ & $0(0)$ & $0(0)$ & $6(100)$ \\
\hline 2 & Carbamazepine & 64 & $45(70.3)$ & $8(12.5)$ & $40(62.5)$ & $11(17.1)$ & $7(10.9)$ & $22(34.3)$ \\
\hline 3. & Clobazam & 44 & $9(20.45)$ & $10(22.7)$ & $40(90.9)$ & - & $0(0)$ & $0(0)$ \\
\hline 4. & Clonazepam & 48 & $7(14.6)$ & $15(31.2)$ & $38(79.2)$ & $4(8.3)$ & $5(10.4)$ & $19(39.6)$ \\
\hline 5. & Diazepam & 40 & $26(65)$ & $25(62.5)$ & $34(85)$ & $33(82.5)$ & $5(12.5)$ & $3(7.5)$ \\
\hline 6. & Eslicarbazepine & 8 & $0(0)$ & $8(100)$ & - & - & $3(37.5)$ & $0(0)$ \\
\hline 7. & Fosphenytoin & 24 & $0(0)$ & $10(41.6)$ & $24(100)$ & $0(0)$ & $3(12.5)$ & $4(16.6)$ \\
\hline 8. & Lacosamide & 14 & $13(92.8)$ & $0(0)$ & - & $3(21.4)$ & $0(0)$ & $12(85.7)$ \\
\hline 9. & Lamotrigine & 48 & $10(20.8)$ & $16(33.3)$ & $48(100)$ & $6(12.5)$ & $7(14.6)$ & $8(16.7)$ \\
\hline 10. & Levitiracetam & 38 & $12(31.6)$ & $4(10.5)$ & $33(86.8)$ & $7(18.4)$ & $13(34.2)$ & $7(18.4)$ \\
\hline 11 & Lorazepam & 17 & $0(0)$ & $9(52.9)$ & $17(100)$ & $2(11.7)$ & $0(0)$ & $0(0)$ \\
\hline 12 & Midazolam & 26 & $0(0)$ & $0(0)$ & $26(100)$ & $3(11.5)$ & $2(7)$ & $0(0)$ \\
\hline 13 & Oxcarbazepine & 27 & $7(25.9)$ & $0(0)$ & $27(100)$ & $8(29.6)$ & $0(0)$ & $2(7.4)$ \\
\hline 14 & Perampanel & 12 & $0(0)$ & $7(58.3)$ & - & - & $0(0)$ & $12(100)$ \\
\hline 15 & Pentobarbital & 5 & $0(0)$ & $0(0)$ & - & $5(100)$ & $0(0)$ & $0(0)$ \\
\hline 16 & Phenobarbital & 42 & $0(0)$ & $24(57.1)$ & $30(71.4)$ & $27(64.3)$ & $17(40.5)$ & $14(33.3)$ \\
\hline 17 & Phenytoin & 53 & $9(17)$ & $44(83)$ & $46(86.8)$ & $25(47.2)$ & $7(13.2)$ & $25(47.2)$ \\
\hline 18 & Propofol & 12 & $0(0)$ & $0(0)$ & $12(100)$ & $6(50)$ & $0(0)$ & $6(50)$ \\
\hline 19 & Sodium Valproate & 55 & $37(67.3)$ & $12(21.8)$ & $23(41.8)$ & $5(9)$ & $5(9)$ & $10(18.2)$ \\
\hline 20 & Rufinamide & 5 & $0(0)$ & $1(2)$ & - & $1(20)$ & $0(0)$ & $5(100)$ \\
\hline 21 & Topiramate & 48 & $1(2)$ & $2(4)$ & $35(72.9)$ & $7(14.5)$ & $6(12.5)$ & $1(2)$ \\
\hline 22. & Zonisamide & 49 & $18(36.7)$ & $7(14.2)$ & $43(87.7)$ & $8(16.3)$ & $7(14.2)$ & $9(18.3)$ \\
\hline
\end{tabular}


Rest of 12 anti-epileptic drugs which are not included in Table 1 include acetazolamide, clorazepate, divalproex, ethosuximide, ezogabine, felbamate, gabapentin, magnesium sulfate, primidone, pregabalin, vigabatrin and tiagabine.

Newer anti-epileptic drugs as per classification given in GG, are 13 in number namely: eslicarbazepine, ezogabine, lacosamide, lamotrigine, levetiracetam, gabapentin, oxcarbazepine, perampanel, vigabatrin, rufinamide, tiagabine, topiramate, zonisamide. Other drugs are acetazolamide, clorazepate, divalproex, ethosuximide, felbamate, magnesium sulfate, primidone and pregabalin.

Some of the drugs to treat various types of epilepsy as per Indian Epilepsy Society are not mentioned in all sources of information like for focal epilepsy, lacosamide, perampenal and eslicarbazepine, pentobarbital for status epilepticus, rufinamide for LGS are not mentioned in
CIMS. Lippincott is deficient in mentioning eslicarbazepine for focal seizures and clobazam for LGS. All sources are deficient in mentioning all ADRs of even important anti-epileptic drugs like phenytoin, pentobarbital, phenobarbital, valproic acid and carbamazepine (Table 2).

CIMS has mentioned separately the serious and the potentially fatal adverse reactions with special mention about their teratogenic effects. All the sources of information have not mentioned complete information on serious and life threatening ADRs. DT \& Lippincott have missed life threatening adverse effects of valproic acid. Lippincott, DT and Brenner \& Stevens have not included serious adverse effects of diazepam while NFI has included only $54.1 \%$ of them. Maximum serious (54.6\%) and life threatening $(59.8 \%)$ ADRs are mentioned in CIMS and minimum number of serious: life threatening ADRs are mentioned in textbooks, Lippincott (8.7: $14.5 \%)$ and Brenner and Stevens (13.5: 8.5\%) (Table 3).

Table 2: Percentage of ADRs mentioned in each source according to type of seizure (classification of seizures and treatment is as per guidelines of Indian epilepsy society $\left.(2017)^{8}\right)$.

\begin{tabular}{|c|c|c|c|c|c|c|c|c|}
\hline Type & Drugs & $\begin{array}{l}\text { Total number } \\
\text { of ADRs } \\
\text { mentioned }\end{array}$ & $\begin{array}{l}\mathrm{NFI}^{\mathbf{8}} \\
(\%)\end{array}$ & $\begin{array}{l}\mathrm{DT}^{9} \\
(\%)\end{array}$ & $\begin{array}{l}\text { CIMS }^{10} \\
(\%)\end{array}$ & $\begin{array}{l}\text { Lippincott }^{11} \\
(\%)\end{array}$ & $\begin{array}{l}\text { Brenner \& } \\
\text { Stevens }^{12}(\%)\end{array}$ & $\begin{array}{l}\mathbf{G G}^{13} \\
(\%)\end{array}$ \\
\hline \multirow{6}{*}{$\begin{array}{l}\text { Focal } \\
\text { seizures }\end{array}$} & Phenytoin & 53 & 9 & 44 & 46 & 25 & 7 & 25 \\
\hline & Carbamazepine & 64 & 70.3 & 12.5 & 62.5 & 17.1 & 10.9 & 34.3 \\
\hline & Oxcarbamazepine & 27 & 25.9 & 0 & 100 & 29.6 & 0 & 7.4 \\
\hline & Lacosamide & 14 & 92.8 & 0 & - & 21.4 & 0 & 85.7 \\
\hline & Eslicarbazepine & 8 & 0 & 100 & - & - & 37.5 & 0 \\
\hline & Brivaracetam & 6 & 0 & 0 & 0 & 0 & 0 & 6 \\
\hline \multirow{3}{*}{$\begin{array}{l}\text { Focal } \\
\text { seizures, } \\
\text { GTC }\end{array}$} & Phenobarbital & 42 & 0 & 57.1 & 71.4 & 64.3 & 40.5 & 33.3 \\
\hline & Perampanel & 5 & 0 & 0 & - & 100 & 0 & 0 \\
\hline & Zonisamide & 49 & 36.7 & 14.2 & 87.7 & 16.3 & 14.2 & 18.3 \\
\hline $\begin{array}{l}\text { Focal, GTC } \\
\text { and } \\
\text { myoclonic } \\
\text { seizures }\end{array}$ & Levetiracetam & 38 & 31.6 & 10.5 & 86.8 & 18.4 & 34.2 & 18.4 \\
\hline \multirow{2}{*}{$\begin{array}{l}\text { Focal, } \\
\text { GTC, LGS }\end{array}$} & Lamotrigine & 48 & 20.8 & 33.3 & 100 & 12.5 & 14.6 & 16.7 \\
\hline & Topiramate & 48 & 2 & 4 & 72.9 & 14.5 & 12.5 & 2 \\
\hline \multirow{2}{*}{ LGS } & Rufinamide & 5 & 0 & 2 & - & 20 & 0 & 100 \\
\hline & Clobazam & 44 & 20.45 & 22.7 & 90.9 & - & 0 & 0 \\
\hline \multirow{9}{*}{$\begin{array}{l}\text { Status } \\
\text { epilepticus }\end{array}$} & Midazolam & 26 & 0 & 0 & 100 & 11.5 & 7 & 0 \\
\hline & Lorazepam & 17 & 0 & 52.9 & 100 & 11.7 & 0 & 0 \\
\hline & Diazepam & 40 & 65 & 62.5 & 85 & 82.5 & 12.5 & 7.5 \\
\hline & Fosphenytoin & 24 & 0 & 41.6 & 100 & 0 & 12.5 & 16.6 \\
\hline & Valproic acid & 55 & 67.3 & 21.8 & 41.8 & 9 & 9 & 18.2 \\
\hline & Levetiracetam & 38 & 31.6 & 10.5 & 86.8 & 18.4 & 34.2 & 18.4 \\
\hline & Phenobarbital & 42 & 0 & 57.1 & 71.4 & 64.3 & 40.5 & 33.3 \\
\hline & Propofol & 12 & 0 & 0 & 100 & 50 & 0 & 50 \\
\hline & Pentobarbital & 5 & 0 & 0 & - & 100 & 0 & 0 \\
\hline
\end{tabular}

\footnotetext{
*GTC: Generalized tonic clonic seizures.
} 
Table 3: A comparison of serious and life-threatening adverse effects mentioned in different sources of information.

\begin{tabular}{|c|c|c|c|c|c|c|c|c|c|c|c|c|c|c|c|}
\hline \multirow{3}{*}{$\begin{array}{l}\text { S. } \\
\text { no }\end{array}$} & \multirow{3}{*}{ Common drugs } & \multirow{2}{*}{\multicolumn{2}{|c|}{$\begin{array}{l}\text { Total } \\
\text { number of } \\
\text { ADRs } \\
\text { mentioned }\end{array}$}} & \multirow{2}{*}{\multicolumn{2}{|c|}{$\begin{array}{l}\text { NFI }^{8} \\
\text { Number (\%) of } \\
\text { ADRS }\end{array}$}} & \multirow{2}{*}{\multicolumn{2}{|c|}{$\begin{array}{l}\text { DT }^{9} \\
\text { Number (\%) of } \\
\text { ADRS }\end{array}$}} & \multirow{2}{*}{\multicolumn{2}{|c|}{$\begin{array}{l}\text { CIMS }^{10} \\
\text { Number (\%) of } \\
\text { ADRS }\end{array}$}} & \multirow{2}{*}{\multicolumn{2}{|c|}{$\begin{array}{l}\text { Lippincott }{ }^{11} \\
\text { Number }(\%) \text { of } \\
\text { ADRS }\end{array}$}} & \multirow{2}{*}{\multicolumn{2}{|c|}{$\begin{array}{l}\text { Brenner \& } \\
\text { Stevens }{ }^{12} \\
\text { Number }(\%) \text { of } \\
\text { ADRS }\end{array}$}} & \multirow{2}{*}{\multicolumn{2}{|c|}{$\begin{array}{l}\mathrm{GG}^{13} \\
\text { Number }(\%) \text { of } \\
\text { ADRS }\end{array}$}} \\
\hline & & & & & & & & & & & & & & & \\
\hline & & $\mathrm{S}$ & LT & $\mathrm{S}$ & LT & $\mathrm{S}$ & $\mathrm{LT}$ & $\mathrm{S}$ & LT & $\mathrm{S}$ & $\mathrm{LT}$ & $\mathrm{S}$ & $\mathrm{LT}$ & $\mathrm{S}$ & LT \\
\hline 1 & Brivaricetam & 6 & 0 & $0(0)$ & $0(0)$ & $0(0)$ & $0(0)$ & $0(0)$ & $0(0)$ & $0(0)$ & $0(0)$ & $0(0)$ & $0(0)$ & $6(100)$ & $0(0)$ \\
\hline 2. & Carbamazepine & 27 & 14 & $12(44.4)$ & $14(100)$ & $3(11.1)$ & $4(28.5)$ & $22(81.4)$ & $8(57.1)$ & $3(11.1)$ & $6(42.8)$ & $2(7.4)$ & $1(7.1)$ & $14(51.8)$ & $4(28.5)$ \\
\hline 3. & Clobazam & 24 & 3 & $6(25)$ & $1(7.1)$ & $4(16.6)$ & $1(33.3)$ & $19(79.1)$ & $2(66.6)$ & $0(0)$ & $0(0)$ & $0(0)$ & $0(0)$ & $2(8.3)$ & $0(0)$ \\
\hline 4 & Diazepam & 24 & 4 & $13(54.1)$ & $3(75)$ & $19(79.1)$ & $3(75)$ & $22(91.6)$ & $2(50)$ & $0(0)$ & $0(0)$ & $0(0)$ & $4(100)$ & $3(12.5)$ & $3(75)$ \\
\hline 5 & Eslicarbazepine & 8 & 1 & $0(0)$ & $0(0)$ & $4(50)$ & $0(0)$ & $0(0)$ & $0(0)$ & $5(62.5)$ & $1(100)$ & $5(62.5)$ & $1(100)$ & $0(0)$ & $0(0)$ \\
\hline 6 & Fosphenytoin & 10 & 8 & $5(50)$ & $3(37.5)$ & $5(50)$ & $4(50)$ & $10(100)$ & $8(100)$ & $0(0)$ & $0(0)$ & $0(0)$ & $0(0)$ & $9(90)$ & $4(50)$ \\
\hline 7 & Lacosamide & 11 & 1 & $5(45.4)$ & $1(100)$ & $0(0)$ & $0(0)$ & - & - & $1(9)$ & $0(0)$ & $0(0)$ & $0(0)$ & $7(63.6)$ & $1(100)$ \\
\hline 8 & Lamotrigine & 18 & 9 & $2(11.1)$ & $4(44.4)$ & $10(55.5)$ & $1(11.1)$ & $18(100)$ & $8(88.8)$ & $2(11.1)$ & $1(11.1)$ & $3(16.6)$ & $1(11.1)$ & $7(38.8)$ & $2(22.2)$ \\
\hline 9 & Levetiracetam & 16 & 8 & $7(43.1)$ & $1(12.5)$ & $2(25)$ & $1(12.5)$ & $15(93.7)$ & $8(100)$ & $4(25)$ & $1(12.5)$ & $3(18.7)$ & $0(0)$ & $6(37.5)$ & $0(0)$ \\
\hline 10 & Lorazepam & 14 & 5 & $0(0)$ & $0(0)$ & $9(64.2)$ & $0(0)$ & $12(85.7)$ & $5(100)$ & $2(28.5)$ & $0(0)$ & $0(0)$ & $0(0)$ & $0(0)$ & $0(0)$ \\
\hline 11 & Midazolam & 13 & 5 & $0(0)$ & $0(0)$ & $0(0)$ & $0(0)$ & $13(100)$ & $5(100)$ & $3(23)$ & $0(0)$ & $2(15.3)$ & $0(0)$ & $2(15.3)$ & $0(0)$ \\
\hline 12 & Oxcarbazepine & 13 & 8 & $5(38.4)$ & $1(12.5)$ & $0(0)$ & $0(0)$ & $10(76.9)$ & $7(87.8)$ & $5(38.4)$ & $1(12.5)$ & $0(0)$ & $0(0)$ & $3(23)$ & $1(12.5)$ \\
\hline 13 & Perampanel & 6 & 1 & $0(0)$ & $0(0)$ & $3(50)$ & $0(0)$ & $0(0)$ & $0(0)$ & $4(66.6)$ & $1(100)$ & $0(0)$ & $0(0)$ & $6(100)$ & $1(100)$ \\
\hline 14 & Phenobarbital & 20 & 11 & $10(50)$ & $11(100)$ & $11(55)$ & $5(45.4)$ & $13(65)$ & $7(63.6)$ & $0(0)$ & $0(0)$ & $5(25)$ & $1(9)$ & $10(50)$ & $0(0)$ \\
\hline 15 & Phenytoin & 25 & 13 & $22(88)$ & $13(100)$ & $18(72)$ & $11(84.6)$ & $15(60)$ & $10(76.9)$ & $17(25)$ & $1(7.6)$ & $7(28)$ & $0(0)$ & $12(48)$ & $3(23)$ \\
\hline 16 & Propofol & 11 & 5 & $0(0)$ & $0(0)$ & $0(0)$ & $0(0)$ & $11(100)$ & $5(100)$ & $5(45.4)$ & $1(20)$ & $5(45.4)$ & $1(20)$ & 7 (63.6) & $2(40)$ \\
\hline 17 & Rufinamide & 3 & 1 & $0(0)$ & $0(0)$ & $0(0)$ & $0(0)$ & $0(0)$ & $0(0)$ & $0(0)$ & $1(100)$ & $0(0)$ & $0(0)$ & $2(66.6)$ & $0(0)$ \\
\hline 18 & Topiramate & 24 & 2 & $15(62.5)$ & $2(100)$ & $16(66.6)$ & $1(50)$ & $22(91.6)$ & $1(50)$ & $2(8.3)$ & $2(100)$ & $5(20.8)$ & $0(0)$ & $2(8.3)$ & $1(50)$ \\
\hline 19 & Zonisamide & 17 & 7 & $10(58.8)$ & $4(57.1)$ & $2(11.7)$ & $0(0)$ & $17(100)$ & $7(100)$ & $7(41.1)$ & $1(14.2)$ & $2(11.7)$ & $0(0)$ & $5(29.4)$ & $2(28.5)$ \\
\hline \multirow[t]{3}{*}{20.} & Valproic acid & 19 & 11 & $19(100)$ & $0(0)$ & $5(26.3)$ & $3(27.2)$ & $9(47.3)$ & $8(72.7)$ & $9(47.3)$ & $0(0)$ & $3(15.7)$ & $1(9)$ & $5(55.5)$ & $3(15.7)$ \\
\hline & Total & 309 & 117 & 131 & 58 & 111 & 34 & 169 & 70 & 27 & 17 & 42 & 10 & 108 & 27 \\
\hline & Percentage $(\%)$ & & & 42.3 & 49.5 & 35.9 & 29.0 & 54.6 & 59.8 & 8.7 & 14.5 & 13.5 & 8.5 & 34.9 & 23.0 \\
\hline
\end{tabular}

Percentage of life-threatening adverse effects mentioned in all sources (maximum number of adverse effects mentioned are taken as $100 \%):$ S: serious adverse effects; $*$ LT: life threatening adverse effects. 


\section{DISCUSSION}

To ensure safe and rational use of drugs, it is important that drug's information sources should be complete in all aspects such as its indications, dosage, ADRs, contraindications and precautions. Safety of patients and safe use of medicines are of prime concern for optimum use of medicines. CDSCO regulates the safety issues of patients and PvPI is concerned with reporting and collection of ADR data in India.

This cross-sectional observational study was undertaken to assess the quantity and quality of drug information about ADRs mentioned in various drug sources. DT and CIMS are commercially available drug information compendiums and showed variability in ADRs.

\section{Quantitative analysis}

GG gave information for maximum number of drugs (26), but having 253 ADRs. 23, 22 and 18 out of 34 drugs were included in Lippincott, DT and NFI respectively. None of the sources mentioned all the antiepileptic drugs. CIMS had included 25 drugs with maximum number of 905 ADRs. Least were mentioned in Brenner \& Stevens' Pharmacology (138) for 21 drugs. In a study done to assess the ADRs information in different sources (Randhawa et al), DT mentioned maximum number of anti-hypertensive drugs (81.8\%) but least ADR information, and number of drugs mentioned were least in $\operatorname{NFI}(29.7 \%) .{ }^{14}$

There was wide variability while listing ADRs, for example, 61 ADRs were mentioned for Gabapentin in CIMS while GG listed only 4 ADRs. CIMS gave 110 ADRs for pregabalin and GG gave only 2 ADRs while it had no mention in NFI \& Stevens and Brenner. DT had included even the recently developed antiepileptics such as magnesium sulphate, eslicarbazepine, ezogabine, perampanel, rufinamide but had missed some important drugs like oxcarbazepine, ethosuximide, felbamate, midazolam.

NFI, CIMS and Lippincott had not included recently developed antiepileptics along with some important antiepileptics such as fosphenytoin, diazepam, phenobarbitone and felbamate.

These sources are showing variability even in giving the information about the lif- threatening adverse effects. CIMS mentions the maximum life-threatening adverse effects $(59.8 \%)$ while the least are mentioned in Stevens and Brenner $(8.5 \%)$.

\section{Qualitative analysis}

All the drug sources under study were found to be incomplete in providing ADRs information. GG included maximum number of drugs (26) but is silent on the adverse effects of few of the drugs, followed by CIMS
(25) and DT (22) which has included even the recently developed drugs. CIMS does not include all the drugs but reports maximum number of the adverse effects and also reports few ADRs which are not mentioned in other sources. Lippincott and Brenner \& Stevens' Pharmacology did not mention all the drugs and mentioned very few of the newer anti-epileptics. These sources failed to include prototype drugs such as midazolam and ethosuximide, which were found missing in DT and NFI and midazolam in GG.

Serious ADRs were analysed in these sources of information. CIMS has mentioned separately the serious and the potentially fatal adverse reactions with special mention about their teratogenic effects. DT has missed serious adverse effects of many important drugs like phenytoin, phenobarbital, oxcarbazepine. CIMS mentions 22 serious adverse effects of carbamazepine while only 3 serious ADRs are mentioned in DT.

Serious ADRs increase morbidity, hospital stay, loss of working days and increase in financial burden. Incomplete knowledge of life-threatening adverse effects can lead to increased morbidity and mortality.

No source of information provided complete information of the 34 drugs studied about adverse effects, even serious and life-threatening ones. All the sources of information showed variability in quantity and quality of ADRs mentioned, thereby, making the selection of appropriate source difficult. Academicians and policymakers can work towards providing complete ADR information in all sources of information and updating it from time to time. Thus, making the drug use safer in patients of epilepsy.

Funding: No funding sources

Conflict of interest: None declared

Ethical approval: Not required

\section{REFERENCES}

1. Amudhan S, Gururaj G, Satishchandra P. Epilepsy in India I: Epidemiology and public health. Ann Indian Acad Neurol. 2015;18:263-77.

2. Adverse effects of antiepileptic drugs. Pharmacovigilance. Available at: https://www. pharmaco-vigilance.eu/content/adverse-effectsantiepileptic-drugs. Accessed on 1 August 2019.

3. Kessler DA. Introducing MEDWatch. A new approach to reporting medication and device adverse effects and product problems. JAMA. 1993;269:2765-8.

4. Guidelines on Adverse Drug Reaction Monitoring and Reporting.:3. Available at: https://www.ashp.org/ -/media/assets/policy-guidelines/docs/guidelines/ adverse-drug-reaction-monitoring-reporting.ashx. Accessed on 21 November 2019.

5. Rohilla A, Kumar V, Sharma MK, Dahiya A, Kushnoor A. Pharmacovigilance: Needs and objectives. J Adv Pharm Educ Res. 2012;2:201-5. 
6. CFR - Code of Federal Regulations Title 21. Available at: https://www.accessdata.fda.gov/scripts/ cdrh/cfdocs/cfcfr/CFRSearch.cfm?fr=312.32. Accessed on 30 June 2019.

7. Suke SG, Kosta P, Negi H. Role of Pharmacovigilance in India: An overview. Online J Public Health Inform. 2015;7(2):e223.

8. Indian Pharmacopoeia Commission, India, editors. NFI: National formulary of India. 4th edition. New Delhi: Indian Pharmacopoeia Commission, Ministry of Health \& Family Welfare, Government of India; 2011: 55-68

9. Mishra L. Drug Today. Lorina Publications (I) Inc.; 2019: 475-530.

10. Search Drug Information, Interactions, Images, Dosage \& Side Effects | CIMS India. Available at: https://www.mims.com/india. Accessed on 21August 2019.

11. Whalen K. Lippincott Illustrated Reviews Pharmacology. 5th ed. Lippincott William \& Wilkins. Wolters Kluwer; 2018: 181-192.
12. Brenner GM, Stevens CW. Pharmacology. 5th ed. Philadelphia, PA: Elsevier; 2018: 217-230.

13. Brunton LL, Knollmann BC, Hilal-Dandan R, editors. Goodman \& Gilman's the pharmacological basis of therapeutics. 13th edition. New York: McGraw Hill Medical. 2018: 303-326.

14. Randhawa GK, Sharma R, Singh NR, Sharma N. A Qualitative and Quantitative Comparison of Adverse Drug Reaction Data in Different Drug Information Sources. Int J Appl Basic Med Res. 2017;7(4):223-7.

Cite this article as: Kullar KK, Kaur P, Singh A, Randhawa GK. A qualitative and quantitative comparison of adverse drug reaction data of antiepileptic drugs in various sources of drug information. Int J Basic Clin Pharmacol 2020;9:315-21. 